\title{
Detection of high-risk pregnancies in low- resource settings: a case study in Guatemala
}

\author{
Patricia Hanna Crispín Milart ${ }^{1}$, Ignacio Prieto-Egido ${ }^{2^{*}}$, Cesar Augusto Díaz Molina ${ }^{3}$ and \\ Andrés Martínez-Fernández ${ }^{2}$
}

\begin{abstract}
Background: Maternal and neonatal mortality is still very high at a global level, even though its reduction is a goal established among the Sustainable Development Goals by the United Nations. In order to improve prenatal care to address this challenge, this article proposes a strategy to detect and refer high risk pregnancies in rural setting through a portable ultrasound system combined with blood and urine strip tests.

Methods: The Healthy Pregnancy project was conceived as a single, explanatory and positivist case study, with a sample of ten thousand pregnant women attended by itinerant nurses of the Departments of Alta Verapaz and San Marcos. These nurses were trained and equipped with 31 portable ultrasound, and blood and urine tests to detect common obstetric pathology. Moreover, two obstetricians were responsible for remotely supervising the quality of prenatal care. Target communities were selected by the Health Directorates of the public health system from those that had the highest maternal mortality in previous years.
\end{abstract}

Results: The project attended to 10,108 women in 2 years and 3 months. 55 twin gestations (0.54\%) were diagnosed. Non-cephalic presentation was found in $14.87 \%$ of the pregnant women attended from week 32 onwards. 20 patients were referred for non-evolutive gestation. An 11.08\% prevalence of anemia was detected. Urine infections were diagnosed in $16.43 \%$ of the cases. Proteinuria was detected in $2.6 \%$ of patients, but only 17 of them presented high blood pressure and were therefore referred with a suspected pre-eclampsia.

Discussion: The results obtained indicate that an intervention of these characteristics makes it possible to improve the quality of care of rural pregnant women in low and middle-income countries.

Conclusion: The results show that with suitable equipment, training, and supervision, the nursing staff in charge of care in rural areas can identify and refer most of the obstetric risks in time, which may contribute to the reduction of maternal mortality.

Trial registration: This research was not registered because it is a case study in which the assignment of the medical intervention was not at the discretion of the investigators.

Keywords: Prenatal care, Maternal mortality, Obstetric ultrasound, Low-income countries, Rural areas

\footnotetext{
* Correspondence: ignacio.prieto@urjc.es

${ }^{2}$ Universidad Rey Juan Carlos, Camino del Molino s/n, Fuenlabrada 28943,

Spain

Full list of author information is available at the end of the article
}

(c) The Author(s). 2019 Open Access This article is distributed under the terms of the Creative Commons Attribution 4.0 International License (http://creativecommons.org/licenses/by/4.0/), which permits unrestricted use, distribution, and reproduction in any medium, provided you give appropriate credit to the original author(s) and the source, provide a link to the Creative Commons license, and indicate if changes were made. The Creative Commons Public Domain Dedication waiver (http://creativecommons.org/publicdomain/zero/1.0/) applies to the data made available in this article, unless otherwise stated. 


\section{Plain ENGLISH summary}

Maternal and neonatal mortality still represents a major problem in most low and middle-income countries, particularly in rural areas. Most of these deaths could be prevented with adequate care before, during and after childbirth. However, this is a difficult task due to the lack of specialists and resources, as well as the time required to reach the hospital in emergency cases. This article analyses a project that implements a screening protocol for the early detection of common obstetric pathologies. The protocol is based on a portable ultrasound system complemented with fast blood and urine strip tests, which, used together, facilitate the detection of the most frequent obstetric risks. Nurses who visit rural communities are trained in the use of these systems and the application of the screening protocol. In the case of high risk being detected, the nurses will refer the patient to a higher-level facility, to receive adequate care before any complications appear. This protocol has been applied to a sample of 10,108 pregnant women in rural areas of the Alta Verapaz and San Marcos Departments (Guatemala). The pregnancy risks detected in this case study are coherent with the literature review, showing that it is possible to improve prenatal care in rural settings of low and middle-income countries.

\section{Background}

The gap in terms of access to adequate sexual and reproductive care represents a violation of human rights which affects millions of women throughout the world, particularly those living in low and middle-income countries. This situation led to the death of 303,000 women in 2015 due to pregnancy-associated causes. Of these women, 99\% lived in low and middle-income countries, where the likelihood of death due to such causes is 30 times higher than in high-income countries [1]. The reduction in the global maternal mortality is a goal established by the United Nations in the Sustainable Development Goals [2] (SDGs), however, nowadays, the reduction rate is not enough in order to reach this goal [3]. The majority of maternal deaths occur in rural settings, and most of them could be prevented with adequate medical care before, during and after childbirth. However, the lack of resources and qualified staff, as well as the difficulty in referring or transferring patients, makes it difficult to ensure the right to quality care in rural communities, where only $56 \%$ of births will receive medical care by qualified staff [4].

Previous works have identified the importance of taking good-quality prenatal care to rural communities, in order to reduce maternal mortality through the training of the staff working in these areas [5]. The guide "WHO recommendations on antenatal care for a positive pregnancy experience" recommends that adequate prenatal care should include assessment of anemia, asymptomatic bacteriuria, gestational diabetes, HIV, tuberculosis, and syphilis as part of the maternal assessment [6]. For fetal assessment, an ultrasound is recommended before week 24 to identify multiple gestation, congenital anomalies, estimate gestational age, fetal malpresentation and placenta previa. It also mentions that ultrasound is the most accurate screening tool not widely available in LMIC.

In particular, adequate prenatal control should detect a prevalence of asymptomatic bacteriuria based on that which is described in the literature, between 2 and $15 \%$ [7]. Women with untreated asymptomatic bacteriuria have a higher risk of developing pyelonephritis, low weight at birth and pre-term childbirth. Multiple pregnancies are associated with pre-term birth and a 7 times greater risk of neonatal death [8]. In a recent prospective study, the multiple pregnancy rate for Guatemala was $0.8 \%$ [9]. The rate of detection of non-cephalic presentation from week 32 onwards should be between 7 and $16 \%$ [10]. Regarding placenta previa, the rate of incidence is $0.5 \%$ [11].

However, the lack of resources in rural communities makes quality care difficult, because it is not possible to conduct conventional blood tests due to the lack of laboratories and the fact that it is not feasible to maintain the cold chain. Moreover, ultrasound tests are not viable, due to the lack of electricity, equipment, and trained staff. To overcome these barriers and reduce maternal mortality, several authors have put forward innovative solutions based on $\mathrm{m}$-health (mobile devices supporting the practice of medicine and public health) and telehealth (the remote use of ICTs, Information and Communication Technologies in the health sector). Through these solutions, they try to improve data collection [12, 13], reinforce the follow-up of pregnant women through SMS [14], facilitate the work of midwives by providing support in decision making [15], evaluate ultrasound tests in an asynchronous manner [16] and improve postchildbirth follow-up through SMS to prevent HIV transmission [17]. However, the articles published have only analyzed their impact on process indicators, and different reviews $[18,19]$ have not been able to find studies that evaluate its effects on maternal mortality. The only study found that assessed the impact of an intervention on maternal mortality [20] is focused on hospitals of reference and cannot be extrapolated to rural regions with a lack of resources.

The authors of this study have previously published a study using a portable ultrasound system complemented with dry blood tests and fast urine strips [21]. In total, 762 pregnant women were tested with the system, and there were no maternal deaths in that sample. Since these results showed a promising trend, it was decided 
that a second phase of the project would be conducted to multiply the number of pregnant women tested by ten. This article presents the results obtained from this second phase of the project, which we have called Healthy Pregnancy.

\section{Methods}

The Healthy Pregnancy project was proposed as a "case study," given the limitations posed when using resources from Multilateral (IADB) and Bilateral (AECID and USAID) Agencies of International Cooperation for Human Development. These agencies forced us to intervene in the areas with the highest maternal mortality in Guatemala and to use all funds in what, in an experimental study, would be the intervention group. We could not have a control group, which limited the research methodology and the scope of it.

Therefore, a single explanatory and positivist case study was designed, with a sample of ten thousand pregnant women attended by the itinerant nurses of the Departments of Alta Verapaz and San Marcos. This sample is not able to provide a statistical generalization, but rather, an analytical one, that will allow us to find new relationships and to induce new proposals that can be contrasted in future experimental studies.

Four research questions were defined:

1) Is the addition of portable ultrasound and blood and urine analysis to the prenatal control performed by nurses in the rural areas of Guatemala a feasible, effective and efficient intervention for the diagnosis of common obstetric pathology?

2) With an adequate training and reinforcement program, and an appropriate information system, is it possible to train nurses to perform basic obstetric ultrasound and obtain high-quality ultrasound studies in most of the care provided?

3) Is the identification of pregnant women with pathology or obstetric risk, and their early reference, an opportunity to reduce maternal mortality?

4) Do pregnant women accept the prenatal control offered? Do the health personnel accept and incorporates it into their daily work?

In order to answer these questions, thirty-one Healthy Pregnancy kits were distributed (for conducting ultrasound, blood and urine tests) among the public health system nurses who conduct prenatal monitoring in the departments (through regular visits every two or three months). The objective was the early identification of patients with obstetric risk and their non-urgent referral to health centers in order to receive appropriate

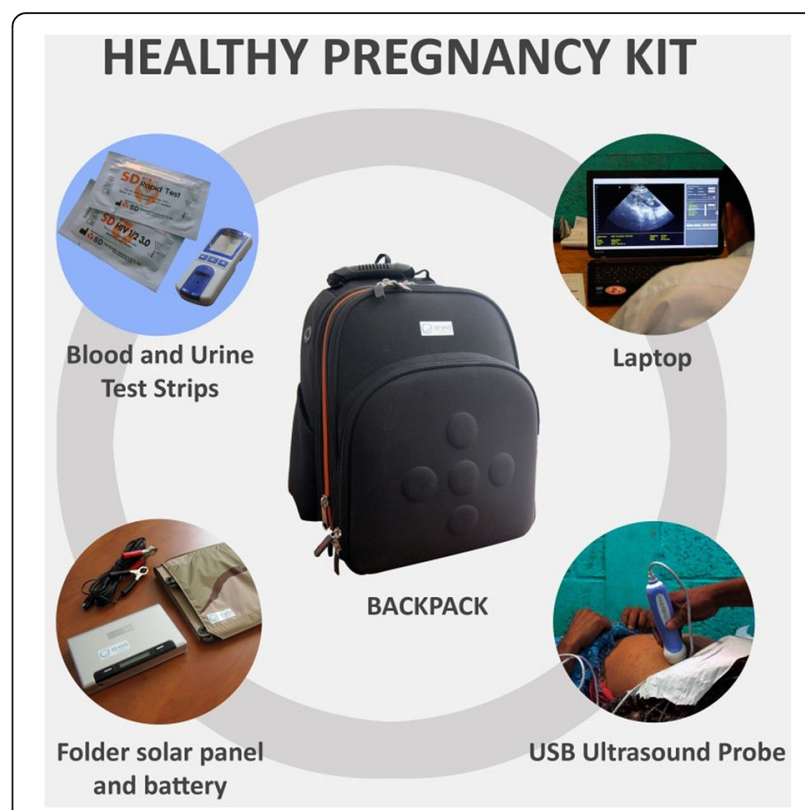

Fig. 1 Materials of the prenatal control kit Healthy Pregnancy. A backpack containing a laptop, USB ultrasound probe, blood and urine rapid tests, two external batteries and a folding solar panel

treatment. In addition to the distribution of equipment, the project carried out training in the use of the diagnostic tools and patient management, as well as remote quality control by two obstetricians located in an urban area.

The Healthy Pregnancy Kit (Fig. 1) is a backpack that contains a laptop, a USB ultrasound probe, a foldable solar panel, an external battery and materials for blood and urine tests. It includes reactive strips with immediate results for HIV, syphilis and HBV, a hemoglobinmeter, a glucometer and urine dipsticks. Each laptop features a Health Information System based on a free software platform (OpenMRS), specially adapted for this project, which allows the recording of data and imaging for each patient tested.

To implement the project 70 nurses were trained through theoretical and practical sessions to evaluate fetal number, cardiac activity, presentation, fetal biometry and placental location. Moreover, two obstetricians were available for the project to supervise the quality of prenatal care. The Health Directorates of the public health system selected target communities among those that had the highest maternal mortality in previous years.

For the evaluation, the following percentages were calculated: fetal malpresentation (defined as all noncephalic presentations from week 32 onwards), multiple pregnancies, cases of placenta previa, the prevalence of anemia, prevalence of UTI, preeclampsia and positive cases in the serology test. Surveys among pregnant 


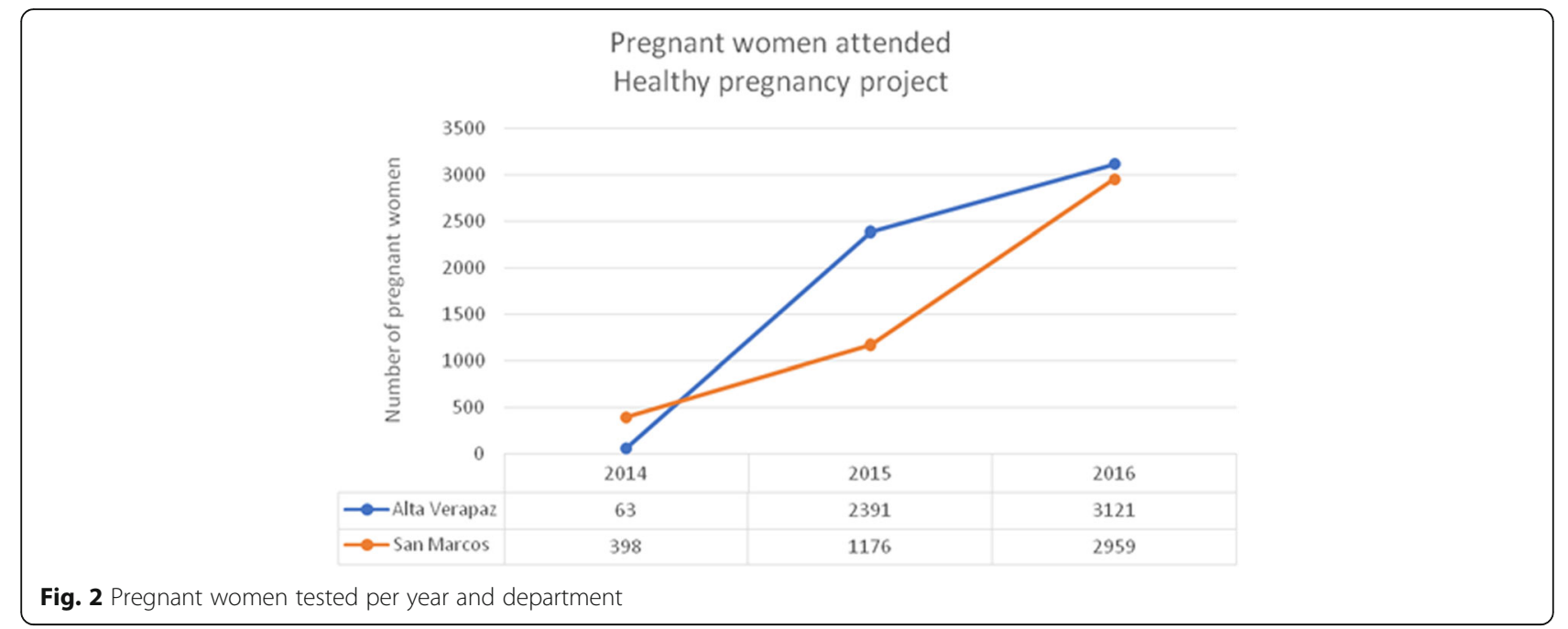

women and nurses were also conducted to evaluate the acceptability of the project.

Maternal Mortality Rate in the Project (MMRP) was defined as the ratio between women who died and had been managed by the project, and the total number of pregnant women managed, multiplied by 100,000.

Table 1 Demographic Details

\begin{tabular}{|c|c|c|}
\hline & $\begin{array}{l}\text { Alta Verapaz } \\
\text { Department }\end{array}$ & $\begin{array}{l}\text { San Marcos } \\
\text { Department }\end{array}$ \\
\hline $\begin{array}{l}\text { Total number of women } \\
\text { tested }\end{array}$ & 5596 & 4512 \\
\hline $\mathrm{Age}^{\mathrm{a}}$ & 25.05 & 25.39 \\
\hline$-<=15$ years old & $161(2.88 \%)$ & $98(2.17 \%)$ \\
\hline - 16-19years old & $1218(21.76 \%)$ & $880(19.50 \%)$ \\
\hline - 20-39 years old. & $4058(72.50 \%)$ & $3386(75.04 \%)$ \\
\hline - > $=40$ years old & $159(2.84 \%)$ & $136(3.01 \%)$ \\
\hline \multicolumn{3}{|l|}{ Parity $^{\mathrm{a}}$} \\
\hline - Nulliparous & $1662(29.70 \%)$ & $1236(27.39 \%)$ \\
\hline $\begin{array}{l}-1-4 \text { previous } \\
\text { childbirths }\end{array}$ & 3147 (56.24\%) & $2679(59.38 \%)$ \\
\hline $\begin{array}{l}-5-9 \text { previous } \\
\text { childbirths }\end{array}$ & $731(13.06 \%)$ & $561(12.43 \%)$ \\
\hline $\begin{array}{l}->=10 \text { previous } \\
\text { childbirths }\end{array}$ & $44(0.79 \%)$ & $30(0.66 \%)$ \\
\hline $\begin{array}{l}\text { Past history of } 1 \text { or more } \\
\text { stillbirths }\end{array}$ & $364(6.5 \%)$ & $316(7 \%)$ \\
\hline \multicolumn{3}{|l|}{ Gestational age at first visit ${ }^{a}$} \\
\hline - 1st trimester & $409(7.30 \%)$ & $525(11.63 \%)$ \\
\hline - 2nd trimester & $2111(37.72 \%)$ & $2187(48.47 \%)$ \\
\hline - 3rd trimester & $3071(54.87 \%)$ & 1798 (39.84\%) \\
\hline
\end{tabular}

*Information on ages was not available for $0.27 \%$ of pregnant women $(N=12)$. Childbirth data was unknown for 18 cases, and in 7 cases women had unknown amenorrhea, and the ultrasound test was not conclusive
Ethical approval for the research protocol was received in July 2012 by the Interagency Committee of Research and Innovation in Health of Alta Verapaz, and all patients gave their written consent to take part in the study before conducting the tests.

\section{Results}

From October 2014 to December 2016, the Healthy Pregnancy project teams tested 10,108 pregnant women. Of those, 55 revealed twin pregnancies and 39 had two pregnancies during the study. The pregnant women tested per department are detailed in Fig. 2. In both departments, we see a clear increase in patient recruitment as the project progressed.

Table 1 shows the demographic details of the population. The mean age of women examined was 25.20 years (SD 6.82), with 11 being the minimum and 47 the maximum age. In our series, adolescent pregnancy reached $21.67 \%$ in the San Marcos Department and 24.63\% in Alta Verapaz. Six hundred and eighty women (6.7\%) had a background of 1 or more stillbirths.

Although the Pregnancy Monitoring Guidelines by the MSPAS recommend recruitment and monitoring of pregnant women from the first trimester, over $90 \%$ of women were seen after 14 weeks, and almost half (48\%) did not have their first visit until the third trimester. The group that started the latest pregnancy control was that of parous women over 39 years old in the department of Alta Verapaz, where $65.4 \%$ had their first visit after 28 weeks. Gestational age presented in Table 1 was estimated with the sonographic study.

\section{Hemoglobin test}

There was an evaluation of $89.96 \%$ of the total population using hemoglobin-meters (a shortage caused the 
Table 2 Hemoglobin and urine test results

\begin{tabular}{|c|c|c|c|c|c|c|}
\hline \multirow{2}{*}{ HEMOGLOBIN TEST } & \multicolumn{2}{|c|}{$\begin{array}{l}\text { Alta Verapaz } \\
(N=5596)\end{array}$} & \multicolumn{2}{|c|}{$\begin{array}{l}\text { San Marcos } \\
(N=4512)\end{array}$} & \multicolumn{2}{|c|}{$\begin{array}{l}\text { Total } \\
N=10,108\end{array}$} \\
\hline & & & & & & \\
\hline Mild anemia $(\mathrm{Hb}<11 \mathrm{~g} / \mathrm{dL})$ & 605 & $10.81 \%$ & 181 & $4.01 \%$ & 786 & $7.78 \%$ \\
\hline Moderate anemia (Hb 7-9,9 g/dL) & 224 & $4.00 \%$ & 101 & $2.24 \%$ & 325 & $3.22 \%$ \\
\hline Severe anemia $(\mathrm{Hb}<7 \mathrm{~g} / \mathrm{dL})$ & 7 & $0.13 \%$ & 2 & $0.04 \%$ & 9 & $0.09 \%$ \\
\hline Normal Hb & 3976 & $71.05 \%$ & 3997 & $88.58 \%$ & 7973 & $78.87 \%$ \\
\hline Not tested & 784 & $14.01 \%$ & 231 & $5.12 \%$ & 1015 & $10.04 \%$ \\
\hline Total anemia cases & 836 & $14.94 \%$ & 284 & $6.29 \%$ & 1120 & $11.08 \%$ \\
\hline \multicolumn{7}{|l|}{ URINE TESTS } \\
\hline Bacteriuria / UTI & 1181 & $21.10 \%$ & 487 & $10.79 \%$ & 1668 & $16.50 \%$ \\
\hline (+) Proteinuria + elevated BP (Pre-eclampsia) & 9 & & 8 & & 17 & $0.17 \%$ \\
\hline Normal results & 3846 & $68.72 \%$ & 3922 & $86.92 \%$ & 7768 & $76.84 \%$ \\
\hline Not tested & 508 & $9.08 \%$ & 89 & $1.97 \%$ & 597 & $5.91 \%$ \\
\hline
\end{tabular}

low coverage). A level of hemoglobin $<11 \mathrm{~g} / \mathrm{dL}$ was detected in $11.08 \%$ of the 10,108 women. Table 2 shows the details of anemia results according to severity. The anemia rate detected in the Alta Verapaz Department was 14.94 and $6.29 \%$ in the San Marcos Department. For the tested patient group, we found an association between adolescent pregnancy and the diagnosis of anemia (OR 1.29, $p<0.05$ ); we did not find differences between nulliparous and parous women. Patients diagnosed with anemia were treated and cases with $\mathrm{Hb}<8 \mathrm{~g} / \mathrm{dl}$ were also advised to attend their health center for follow-up.

\section{Urine tests}

In total, 9512 urine tests were conducted, and urine infections were diagnosed in 1668 cases (16.43\%). We considered a test to be pathological when 2 or $3+$ leukocytes and/or positive nitrites were present. The results with $1+$ in leukocytes were classified as sample contamination to improve test specificity. Proteinuria was detected in $2.6 \%$ of patients (263 results); of these, 17 presented high blood pressure and were therefore diagnosed as suspected pre-eclampsia. Another 180 samples tested positive for proteinuria with normal blood pressure, and since they presented findings compatible with urinary tract infection (UTI), they were dealt with accordingly. The urine test results are shown in Table 2 . Patients with a diagnosis of UTI were treated, and patients with suspected pre-eclampsia were referred to the health center.

\section{Glucose test}

A common practice for screening gestational diabetes is to conduct the O'Sullivan Test (administration of $50 \mathrm{~g}$ of glucose and measuring glycaemia rise after $1 \mathrm{~h}$ ). Given the difficulty in rural settings to find fasting patients, the project used the same cut-off point as the O'Sullivan
Test $(140 \mathrm{mg} / \mathrm{dl})$. The objective was to screen patients at risk and then refer them to a higher-level healthcare center for diagnosis. It was decided that the benefits of screening with this approach were higher than not conducting it all. In total, 9942 tests were conducted. In the case of Alta Verapaz, $10(0.08 \%)$ patients were identified with glucose $>=140$, and $17(0.38 \%)$ in San Marcos.

\section{Screening for serologies}

There were 9304 tests conducted for HBV, 8878 for syphilis and 9373 for HIV. Of these, 24 patients showed positive results and were advised to undergo a confirmation test at their health center. In total, 13 cases were confirmed: 7 for HBV, 2 for syphilis and 4 for HIV. Seven (7) tests were false positives, and at the data collection deadline, there was no confirmed answer for 4 patients.

\section{Other results}

Fifty-five (55) twin pregnancies were detected: 38 in the Alta Verapaz Department (0.67\%) and 17 in San Marcos $(0.37 \%)$. A consensus was reached in the healthcare protocol to refer all non-cephalic cases $>32$ weeks for delivery to healthcare centers. In total, there were 454 women: 329 in Alta Verapaz and 125 in San Marcos. The overall rate of fetal malpresentation was $4.49 \%$ of the women tested, which corresponded to $14.87 \%$ of the pregnant women attended from week 32 onwards.

Twenty (20) patients were referred for non-viable pregnancy: 2 stillbirths (25 and 26-week-old fetuses), 3 late miscarriages and 3 cases suspected to be molar pregnancies, 2 anembryonic pregnancies, 3 miscarriages during the first trimester and 7 patients with $>10$-week amenorrhea where no pregnancy was detected. Seven women were diagnosed and referred because of placenta previa in the third trimester. 
Percentage of good-quality ultrasound tests per semesters.

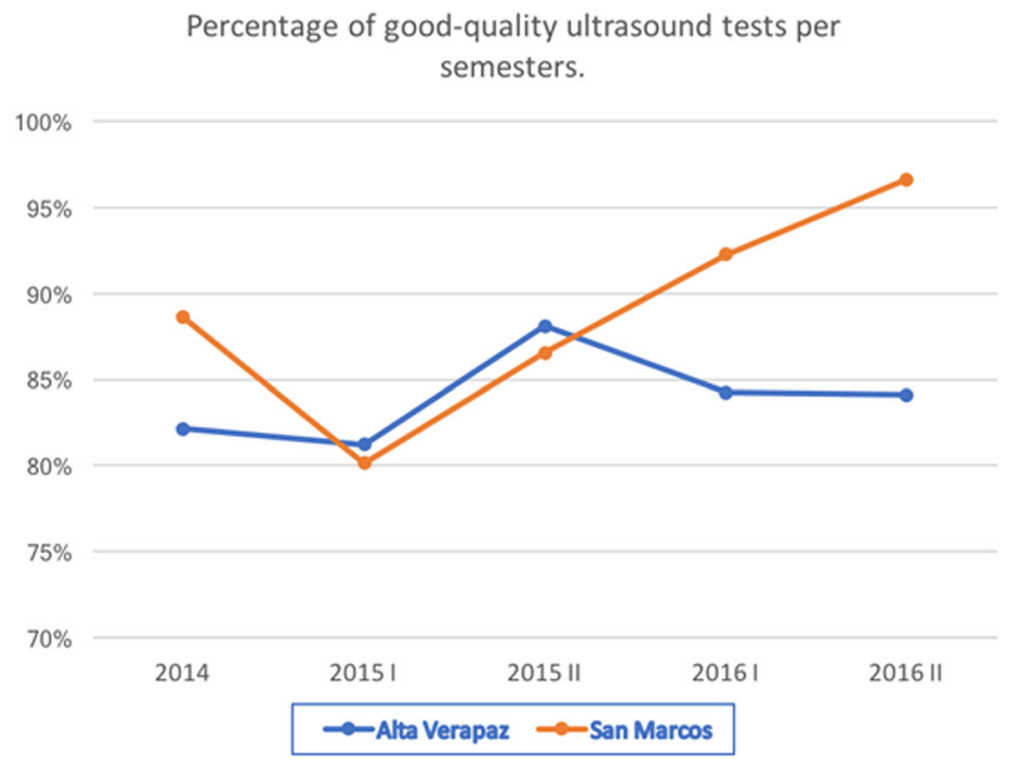

Fig. 3 Percentage of good-quality ultrasound tests per semesters

Even though the detection of fetal malformations was not one of the objectives of the project, nurses received basic notions of fetal morphology during their training. It was considered logical for the numerous basic studies to enable nurses to develop skills for detecting severe malformations. As a result, 11 pregnant women were referred for suspected fetal malformation: 5 suspected anencephalies, 4 findings of hydrocephaly and 2 cases of gastroschisis (one in a hydropic abortion at 17 weeks).

Quality control was conducted on $100 \%$ of the 10,108 tests by two obstetricians using the information system of the project. Quality assessment for the ultrasound tests took place at 4 levels: (1) The four biometry images are correct; (2) At least 3 acceptable images; (3) Only one acceptable image, or (4) No quality ultrasound. It was considered that a good ultrasound test should receive a score of (1) or (2). Figure 3 shows the progression per semester of the proportion of good-quality ultrasound tests. A clear improvement was observed during the project for nurses in the San Marcos Department, and there was a sustained level of quality in the Alta Verapaz Department.

For the calculation of MMRP, 8995 women with an estimated date of delivery (EDD) up to December 31, 2016 were considered. Therefore, the study excluded 1113 women with a subsequent EDD (620 in SM and 493 in $\mathrm{AV}$ ).

The total number of pregnant women who died was 9 , which resulted in a MMRP of 100.05 per 100,000 live births. There were 4 deaths recorded in the SM Department in our group of 3892 women and 5 cases in the group of 5103 women in the Alta Verapaz Department.
A total of 192 pregnant women were interviewed to evaluate the acceptability of the Healthy Pregnancy Kit 96 in each of the two departments. 50 of the 192 women surveyed were nulliparous, and among the remaining women (142) only 49 (34.5\%) had access to an ultrasound in their previous pregnancies. To the question "what rating would you give in general to the attention received?" a total of $98 \%$ of the women interviewed answered with the following results: good (54\%), very good (25\%) or excellent $(19 \%)$, therefore it can be said that pregnant women are satisfied with the care received. It is important to highlight that $99.4 \%$ of women answered that they would recommend the tests to other women in their communities.

Regarding the nurses that participated in the project, they agree $(25 \%)$ or strongly agree $(75 \%)$ that the equipment provided by the project is easy to use. In addition, they also agree $(31 \%)$ or strongly agree $(69 \%)$ that the follow-up and advice received from the specialist who performs quality control have improved their training and helped them to better define the diagnosis. Overall, 100\% of the nurses are satisfied with the project and believe that it contributes to their professional growth and that it also helps to improve maternal health care of their areas.

The complete Healthy Pregnancy kit has a cost of \$ 5000 , and it makes it possible to carry out 300 prenatal controls per year. Estimating a repayment period of 4 years, this is $\$ 4.1$ per woman attended. The cost of attending each woman during a complete gestation amounts to $\$ 28.7$ per pregnant woman since we need to add to the previous value: strip tests $(\$ 8.7)$, personnel and repairs. 
Table 3 Maternal Mortality

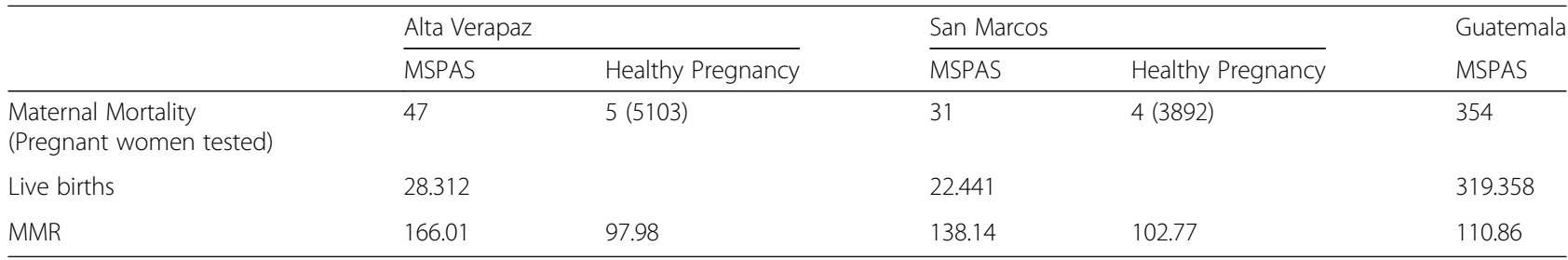

\section{Discussion}

Alta Verapaz and San Marcos are two of the 3 departments in Guatemala with the highest maternal mortality. The Healthy Pregnancy project started working in the districts with the highest number of deaths of pregnant women and newborn. After 3 years, this study has verified a MMRP of 97.98 in Alta Verapaz and 102.77 in San Marcos.

Without the objective of making a statistically significant comparison, Table 3 shows the mortality data in our project, compared to the official MMR data in 2015 (the latest official figure) for both departments, published in the Report of Activities by the MSPAS [22]. In Table 3, we also show the MMR data for the country of Guatemala, obtained from the same source.

The results of this work confirm the trend already detected in the first pilot project carried out in 2012 and 2013 [21].

It is essential to highlight that case studies, such as the one carried out in this research, cannot be used to contrast known theories or proposals, but are instead useful for proposing new research hypotheses that will have to be tested in future experimental studies. The intention, therefore is not to achieve a statistical generalization, but, rather, an analytical one, generalizable only to other cases that present theoretical conditions similar to the present. Even so, the facts described in this paper hint at the possibilities offered by these types of projects for reducing maternal mortality among pregnant women in rural areas of low and middle-income countries.

It was particularly relevant for this study to confirm if the technology, training and new procedures implemented by the Healthy Pregnancy project allow rural nurses to detect most of the obstetric complications. This project has identified a rate of $16.43 \%$ of asymptomatic bacteriuria which is slightly higher than the one usually reported (between 2 and 15\%). The rate of multiple pregnancies identified was $0.54 \%$, which is marginally lower than the one registered for Guatemala $(0.8 \%)$. The rate of detection of fetal malpresentation from week 32 onwards (14.87\%) was consistent with that previously described in the background section, which is between 7 and 16\%. Regarding the glucose tests, the results were far lower than the ones described in the literature, and therefore a modification in the project is being conducted to carry out the test only on fasting women (if they have eaten previously, the test is not performed).

The "Healthy Pregnancy" project enables detection of some important obstetric complications in time, facilitating the referral of pregnant women at a high risk of losing their own lives or the lives of their newborn children. In this sense, we consider that this project contributes to the improvement of prenatal control offered to women in rural areas.

\section{Conclusion}

Rural areas of Guatemala still show high levels of maternal mortality and the public health system lacks the resources to offer ultrasounds, blood tests and specialized medical attention to all women living in these areas. The Healthy Pregnancy initiative proposes a strategy to improve prenatal care in this context by providing equipment, training, and supervision to nurses who are already responsible for prenatal controls in such areas. This case study shows that, with this strategy, the nursing staff can identify and refer most of the obstetric risks in time, which may contribute to the reduction of maternal mortality.

The EHAS Foundation is currently working to extend the project to other Guatemala departments, as well as to other countries in Latin America and Africa. Nowadays, the project has been wholly transferred to the Health Directorates of the Alta Verapaz and San Marcos departments, and patient care is conducted practically without any external financial support, under the responsibility of the relevant Public Health Management Departments.

Additional file 1 contains a Spanish version of this original article.

\section{Additional file}

Additional file 1: Translation of this article into Spanish. (DOCX $376 \mathrm{~kb}$ )

Abbreviations

BP: Blood Pressure; EDD: Estimated Date of Delivery; Hb: Hemoglobin; HBV: Hepatitis B Virus; HIV: Human Immunodeficiency Virus; ICT: Information and Communication Technologies; MMRP: Maternal Mortality Rate Project; MSPAS: Ministry of Public Health and Social Assistance; SDG: Sustainable Development Goals; UTI: Urinary Tract Infections 


\section{Acknowledgments}

We acknowledge the support of the Health Directorates of the Alta Verapaz and San Marcos Departments. The study would not have been possible without the collaboration of the Directorate Representatives and the staff nurses at the public health facilities. The work carried out by the personnel of TulaSalud Association and EHAS Foundation has also been crucial. Finally, we would also like to thank Javier Arturo Entrecanales and Sandrine Woitrin for their financial support to transfer the Healthy Pregnancy initiative to the public system in order to make it sustainable in the long term.

\section{Authors' contributions}

PC designed data collection tools contributed to the collection, filtering, and analysis of the data, and the first draft. IP contributed to designing the data collection tools, monitoring of data collection, analysis of the data and to the writing and review of the draft paper. CD designed data collection tools, provided access to health information from the Alta Verapaz and San Marcos Directorate of Health and monitored data collection. AM conceived the study idea, contributed to the collection and analysis of the data, and the writing and review of the paper. All authors read and approved the final manuscript.

\section{Funding}

This project has been funded by the Spanish Agency for International Development Cooperation (13-PR1-0233), the Multilateral Investment Fund of the Inter-American Development Bank Group (ATM/ME-14532-GU), the United States Agency for International Development (AID-OAA-F-14-00014) and by the Universidad Politécnica de Madrid.

\section{Availability of data and materials}

The datasets used and/or analyzed during the study are available from the corresponding author upon reasonable request.

\section{Ethics approval and consent to participate}

Ethics approval for the research protocol was received in July 2012 by the Interagency Committee of Research and Innovation in Health of Alta Verapaz. All patients in the intervention group who were visited by nurses gave their written consent to take part in the study before conducting the tests. This information is available to the Editors upon request.

\section{Consent for publication}

Not applicable: individual information has not been published.

\section{Competing interests}

The authors declare that they have no competing interests.

\section{Author details}

'Obstetrics and Gynecology Unit, Fundación Alcorcón University Hospital, C/ Budapest, 1, 28922 - Alcorcon, Madrid, Spain. ${ }^{2}$ Universidad Rey Juan Carlos, Camino del Molino s/n, Fuenlabrada 28943, Spain. ${ }^{3}$ Tulasalud non-governmental organization. Alta Verapaz, Guatemala, 6ta. Calle 3-42 Zona 4, Cobán, Alta Verapaz, Guatemala.

\section{Received: 1 August 2018 Accepted: 31 May 2019}

Published online: 11 June 2019

\section{References}

1. Trends in maternal mortality: 1990 to 2015: estimates by WHO, UNICEF, UNFPA. World Bank Group and the United Nations population division. Geneva: World Health Organization; 2015. p. ISBN 9789241565141.

2. United Nations. Sustainable development goals (SDG). 2015. https:// sustainabledevelopment.un.org. Accessed 15 July 2018.

3. United Nations. The millennium development goals report 2015. New York 2015. ISBN 978-92-1-101320-7.

4. Lassi ZS, Das JK, Salam RA, Bhutta ZA. Evidence from community level inputs to improve quality of care for maternal and newborn health: interventions and findings. Reprod Health. 2014;11(2):S2.

5. Lassi ZS, Mansoor T, Salam RA, Das JK, Bhutta ZA. Essential pre-pregnancy and pregnancy interventions for improved maternal, newborn and child health. Reprod Health. 2014;11(1):S2.

6. World Health Organization. WHO recommendations on antenatal care for a positive pregnancy experience. World Health Organization, 2016.
7. Rogozinska E, Formina S, Zamora J, Mignini L, Khan KS. Accuracy of onsite tests to detect asymptomatic bacteriuria in pregnancy: a systematic review and meta-analysis. Obstet Gynecol. 2016;128(3):495-503.

8. American College of Obstetricians and Gynecologists. Multifetal gestations: twin, triplets, and higher-order multifetal pregnancies. 2016. Practice bulletin no. 169. Obstet Gynecol. 128:e131-46.

9. Marete I, Tenge C, Pasha O, et al. Perinatal outcomes of multiple gestation pregnancies in Kenya, Zambia, Pakistan, India, Guatemala and Argentina: a global network study. Am J Perinatol. 2014;31(2):125-32. https://doi.org/10. 1055/s-0033-1338173.

10. Hickok DE, et al. The frequency of breech presentation by gestational age at birth: a large population-based study. American Journal of Obstetrics \& Gynecology. 1992;166(3):851-2.

11. Silver RM. Abnormal placentation: placenta previa, vasa previa, and placenta accreta. Obstet Gynecol. 2015;126(3):654-68.

12. Medhanyie AA, Little A, Yebyo $H$, et al. Health workers' experiences, barriers, preferences and motivating factors in using mHealth forms in Ethiopia. Hum Resour Health. 2015;3:2.

13. Van Heerden A, Norris S, Tollman S, et al. Collecting maternal health information from HIV-positive pregnant women using mobile phone-assisted face-to-face interviews in southern Africa. J Med Internet Res. 2013;15:116.

14. Ngabo F, Nguimfack J, Nwaigwe F, et al. Designing and implementing an innovative SMS-based alert system (RapidSMS-MCH) to monitor pregnancy and reduce maternal and child deaths in Rwanda. Pan Afr Med J. 2012;13:31.

15. Vélez O, Okyere PB, Kanter AS, et al. A usability study of a mobile health application for rural Ghanaian midwives. J Midwifery Womens Health. 2014; 59:184-91.

16. Solano M, Kim E, Christiansen M, et al. Asynchronous telemedicine with ultrasound: improving maternal health in developing countries. Ultrasonics Symposium (IUS), 2009 IEEE International. 2009:2316-9.

17. Odeny TA, Bukusi EA, Cohen CR, Yuhas K, Camlin CS, McClelland RS. Texting improves testing: a randomized trial of two-way SMS to increase postpartum prevention of mother-to-child transmission retention and infant HIV testing. AIDS (London, England). 2014;28(15):2307-12. https://doi.org/10. 1097/QAD.0000000000000409.

18. Tamrat T, Kachnowski S. Special delivery: an analysis of mhealth in maternal and newborn health programs and their outcomes around the world. Matern Child Health J. 2012;16(5):1092-101.

19. Ag Ahmed MA, Gagnon MP, Hamelin-Brabant L, Mbemba Gl, Alami H. A mixed methods systematic review of success factors of mhealth and telehealth for maternal health in sub-Saharan Africa. mHealth. 2017;3(1):22

20. Dumont A, Fournier P, Abrahamowicz M, Haddad S, Fraser WD. Quality of care, risk management, and technology in obstetrics to reduce hospitalbased maternal mortality in Senegal and Mali (QUARITE): a clusterrandomised trial. Lancet. 2013;382:146-57.

21. Crispín PH, Diaz CA, Prieto-Egido I, Martínez-Fernández A. Use of a portable system with ultrasound and blood tests to improve prenatal controls in rural Guatemala. Reprod Health. 2016;13:110.

22. Ministry of Public Health and Social Assistance. National Center of epidemiology. Department of Epidemiological Surveillance. Memory of vital statistics and epidemiological surveillance. Basic Indicators of Analysis of Health Situation Republic of Guatemala, 2.015. Annual Activities 2015.

\section{Publisher's Note}

Springer Nature remains neutral with regard to jurisdictional claims in published maps and institutional affiliations.

Ready to submit your research? Choose BMC and benefit from:

- fast, convenient online submission

- thorough peer review by experienced researchers in your field

- rapid publication on acceptance

- support for research data, including large and complex data types

- gold Open Access which fosters wider collaboration and increased citations

- maximum visibility for your research: over $100 \mathrm{M}$ website views per year

At $\mathrm{BMC}$, research is always in progress.

Learn more biomedcentral.com/submissions 